\title{
Chapter 1 \\ Seven Steps Toward Inclusive, Innovative, and Sustainable Growth
}

\author{
Mark Sanders, Axel Marx and Mikael Stenkula
}

\begin{abstract}
In this chapter, the editors introduce and motivate the approach in this volume. Although this volume brings together contributions from different authors, the chapters all flow directly from the work that was done in the European H2020 research project Financial and Institutional Reforms for the Entrepreneurial Society that was conducted between 2015 and 2018. The first four chapters present and illustrate the multidisciplinary tools that fill the diagnostic toolkit developed in the project. Then three chapters illustrate how these tools can be usefully applied in different institutional contexts in the European Union, namely in Italy, Germany, and the UK.
\end{abstract}

Keywords Entrepreneurship • Entrepreneurship policy

\subsection{Introduction}

A good 50 years after its birth, the European Union is, arguably, in a serious midlife crisis. The global financial crash of 2007-2008 plunged several member states in a prolonged recession and the Syrian crisis strained already troubled relationships in the European family. With the Brexit referendum, the rise of Alternative für Deutschland, populist movements in Spain, Italy, and Greece and the revolt of the Gilets Jaunes in France, it is fair to conclude that Europe is losing its appeal among a vocal and perhaps growing share of European citizens. We believe that this decade of discontent is rooted in feelings of injustice and of being confronted with decisions and their consequences, rather than being involved in them. The solution in a globalizing

M. Sanders ( $\varangle)$

Utrecht School of Economics, Utrecht University, Utrecht, The Netherlands

e-mail: m.w.j.1.sanders@uu.nl

\author{
A. Marx \\ Leuven Centre for Global Governance Studies, University of Leuven, Leuven, Belgium \\ e-mail: axel.marx@ @uleuven.be \\ M. Stenkula \\ Research Institute of Industrial Economics, Stockholm, Sweden \\ e-mail: mikael.stenkula@ifn.se \\ (C) The Author(s) 2020


world, however, is not a retreat to the nation-state. Europe needs to deliver on its initial promise of providing security, well-being, and opportunity for all European citizens. We believe that doing so is also our best chance of restoring Europe on the path to innovative, inclusive, and sustainable growth.

Between 2015 and 2018, some 40 researchers in 9 institutions and countries across Europe have worked on the Horizon2020 project Financial and Institutional Reforms for the Entrepreneurial Society (FIRES; www.projectfires.eu). The chief aim of FIRES was to translate the insights of some three decades of entrepreneurship research into actionable institutional reform proposals. In the project, a strategy was formulated to bring inclusive, sustainable, and innovative growth back to the European Union by reforming Europe's institutions to promote a more open, contestable Entrepreneurial Society. This book, together with its companion volume published as The Entrepreneurial Society: A Reform Agenda for the European Union, presents the core results of this project in a comprehensive way.

In the companion volume, FIRES-researchers Niklas Elert, Magnus Henrekson and Mark Sanders introduced and motivated 50 proposals for reform in six key areas of policy making (Elert et al. 2019). These six areas go well beyond the areas that policymakers traditionally associate with entrepreneurship policy. They give us a list of possibly useful interventions that would have to be implemented at different levels in the European Union. In recognition of the complexity of multilayered policy competencies in the European Union, the authors carefully analyzed the relevant policy-making institutions and their legal and political competencies on the six areas of policy making identified in that volume.

Inevitably, however, these proposals are general and motivated from a broad base of evidence and scientific debate. The resulting menu of options, therefore, should still not be interpreted as a blueprint for a reform strategy that will work in all EU Member States and regions. It would be naive and possibly even damaging to implement all reforms in all regions across the very diverse entrepreneurial ecosystems of the European Union. Each region and state has its specific history and institutional trajectory, and we have therefore always stressed the need for tailoring reforms to local needs and conditions.

In this volume, we collect, present, and illustrate the application of the tools we have developed to do so. Before one can decide what reforms are most suitable in any given context, one needs to distinguish the deep rooted from the more reformable institutions in a region and identify the strengths, weaknesses, and bottlenecks in Europe's entrepreneurial ecosystems. Doing so requires a multidisciplinary approach and the tools illustrated in this volume therefore build on such diverse disciplines as history, geography, economics, and law. 


\subsection{The FIRES Seven-Step Procedure}

In our project, we presented a seven-step approach to formulating an effective reform strategy:

- Step 1: Assess the most salient features of the institutions of a country or region and trace their historical roots.

- Step 2: Assess the strengths and weaknesses of the institutions and flag the bottlenecks in the entrepreneurial ecosystem using structured data analysis.

- Step 3: Identify, using careful primary data collection among entrepreneurial individuals, the most salient features characterizing the start-up process and the barriers that entrepreneurs face.

- Step 4: Map the results of Steps 2 and 3 onto a menu of evidence-based policy interventions to identify suitable interventions for the region or country under investigation.

- Step 5: In light of the historical analysis under Step 1, fit the proposed reforms to the existing local, regional, and national institutional setup.

- Step 6: Identify the relevant policymakers and procedures, i.e., who should change what and in what order for the reform strategy to achieve the greatest chance of success.

- Step 7: Experiment, evaluate, and learn—and return to Step 1 for the next iteration.

With a menu of options and corresponding attribution to the adequate policy making levels in place, we can use this seven-step approach, to formulate an effective reform strategy tailored to the needs of a specific country or region. The book before you shows how to prioritize and adjust the broad, evidence-based menu of reforms presented in Elert et al. (2019) to the specific Member States across Europe.

\subsection{Book Outline}

In Part One of this volume, consisting of four chapters, we discuss how we addressed Steps 1-3 in the FIRES project. This part of the book sets the stage and illustrates how the FIRES-toolbox can be used to diagnose weaknesses in an entrepreneurial ecosystem and select reforms to strengthen them. In the three chapters that make up Part Two of this book, we apply these tools and go through the cycle from Steps 1 to 6 for three countries-Italy, Germany and the UK-representing three rather distinct institutional clusters in the European Union. As we cannot actually implement the proposed policies to execute Step 7, this step is outside the scope of this book, but how this is to be done responsibly is briefly discussed in our conclusion.

In Chap. 2, Selin Dilli illustrates the importance of historical research in Step 1 for institutions shaping the allocation of labor, knowledge, and finance in Europe. Historical research shows that the differences in these institutions are often the result of long-term historical processes. A reform strategy can only be successful if it builds on these historical foundations. Using the Varieties of Capitalism (VoC) framework, 
the chapter provides insight into the different patterns of institutional change and its implications for different forms of entrepreneurial activity across European countries. The historical approach presented in Chap. 2 constitutes the first step in designing a tailored reform strategy.

In Chap. 3, Attila Varga, László Szerb, Tamás Sebestyén and Norbert Szabó present the Regional Entrepreneurship and Development Index (REDI) methodology for assessing the quality of the entrepreneurial ecosystem at the regional level in step 2. In this chapter, the authors also show how improvements in the ecosystem generate macroeconomic impacts in a Geographic Macro Regional (GMR) model simulation. The focus of the analysis here is more on the cross-sectional and geographical dimension. The simulations communicate an important message to policy makers by demonstrating that the impact of reforms will vary across regions and countries in Europe, creating a tension between the level at which policies can be implemented and where they generate positive or negative impacts.

In Chap. 4, Andrea M. Herrmann illustrates how "varieties of entrepreneurial ecosystems" form distinct institutional constellations that facilitate different types of entrepreneurship. More specifically, she stressed that slow-growing incrementally innovative ventures constitute a distinct type of entrepreneurship next to radically innovative, high-growth entrepreneurship. This reveals a second potential tension in formulating reform proposals that build on existing strengths or rather strengthen existing weaknesses. These findings invite policy makers to target entrepreneurial support measures more specifically to their economy's institutional environment and carefully consider institutional complementarities that exist in different varieties of entrepreneurial ecosystems.

To conclude Part One of this volume, Axel Marx presents a legal analysis of European entrepreneurship policy in Chap. 5. In this chapter, he elaborates on how European policy making should be affected when implementing reforms. Changing the institutional environment responsible for the quality of the entrepreneurial ecosystem will require changes on multiple levels. The chapter shows that fostering entrepreneurship will require a multi-level approach with a strong focus on the level of EU Member States.

In Chap. 6, representing the first chapter of Part Two, Mark Sanders, Mikael Stenkula, and co-authors outline a reform strategy to promote a more entrepreneurial society in Italy, classified as a Mixed or Mediterranean Market Economy (MME). Italy historically boasts a vibrant entrepreneurial economy of locally embedded, often family-owned small- and medium-sized firms. But the Italian entrepreneurial ecosystem has a bureaucratic business environment that feeds back into low levels of productivity and ambition in entrepreneurship. To address the problem, Italy could reform its educational system to promote a more experimental attitude and reduce the bureaucratic business environment and recruitment culture that stifles ambitious entrepreneurs. For Italy, important tensions arise between the tendency for entrepreneurial venturing to concentrate in already well-off regions and creating opportunities for all Italians. 
Mark Sanders, Mikael Stenkula, and co-authors follow up in Chap. 7 with a reform strategy to promote a more entrepreneurial society in Germany. Germany can be classified as a coordinated market economy (CME) and is historically characterized by a strong and regionally embedded Mittelstand and an economy where high productivity growth is driven by on-the-job learning and firm-specific skill accumulation. Germany's entrepreneurial talent could be encouraged to take on more risk. The education system could promote creativity, and a more equal playing field between new and incumbent ventures in attracting finance, labor, and knowledge could be created. For Germany, an important tension exists between supporting its traditional incrementally innovative Mittelstand and channeling resources into somewhat riskier and radically innovative ventures to also push out the global technology frontier.

In Chap. 8, Mark Sanders, Mikael Stenkula, and co-authors finally present a reform strategy to promote an entrepreneurial society in the UK. The UK is typically classified as a liberal market economy (LME) and has a deregulated environment, flexible labor markets, well-funded elite universities, and strong protection of intellectual property rights. The UK should aim at strengthening the workforce's knowledge base and talent pool as well as the capital base. It furthermore is advisable to open opportunities for not only starting but also for growing, perhaps less radically innovative, firms in all regions in the UK. For the UK, both the geographical and the variety of entrepreneurship tension will require careful consideration in designing and evaluating our proposed reforms.

The country case studies in Chaps. 6-8 are substantially shortened and reworked versions of the country reports that were submitted as reports to the European Commission and published earlier on www.projectfires.eu, where the reader can also find the policy briefs and a report on the policy round tables that were organized around them in the spring of 2018 in Rome, Berlin, and London, respectively. For the purpose of this book, this material has been merged and significantly revised and updated.

We conclude this volume with Chap. 9, where the editors of the book sum up the main points concerning theory, method, and policy proposals. The editors also elaborate on tensions that exist between the chapters.

\section{Reference}

Elert N, Henrekson M, Sanders M (2019) The entrepreneurial society: a reform strategy for the European Union. Springer, Berlin 
Open Access This chapter is licensed under the terms of the Creative Commons Attribution 4.0 International License (http://creativecommons.org/licenses/by/4.0/), which permits use, sharing, adaptation, distribution and reproduction in any medium or format, as long as you give appropriate credit to the original author(s) and the source, provide a link to the Creative Commons license and indicate if changes were made.

The images or other third party material in this chapter are included in the chapter's Creative Commons license, unless indicated otherwise in a credit line to the material. If material is not included in the chapter's Creative Commons license and your intended use is not permitted by statutory regulation or exceeds the permitted use, you will need to obtain permission directly from the copyright holder.

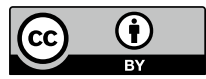

